\title{
Comparative Study of Applying Methods of Measuring Development in Regional Studies: A Case Study of 15 Regions in Isfahan
}

\author{
Mehdi Momeni \\ Faculty of Humanities, Najafabad Branch, Islamic Azad University, Najafabad, Isfahan, Iran \\ momeni100@gmail.com \\ Asma Jafari \\ Faculty of Humanities, Najafabad Branch, Islamic Azad University, Najafabad, Isfahan, Iran
}

\section{Doi:10.5901/mjss.2015.v6n1s1p363}

\begin{abstract}
The wave of using quantitative models in social sciences during the 1960s along with issues of development and underdevelopment expanded the application of these methods in determining the degree or level of development. The present study aims at investigating and comparing some of the methods for determining the degree of development (Morris, Taxonomy) and addressing the question whether all methods yield similar results in determining the level of development. To do so, the level of development of regions in Isfahan was determined by selecting a variable in the form of 9 indexes of development and applying the data in each of the studied methods. The comparison of the results obtained by each of the methods shows that the degree or level of development in the studied areas is different from one method to another due to the type, or nature and the difference in measuring the indexes, and the peculiarities and specific features of each region. Therefore, it is necessary to take precautions in applying models, and quantitative methods, and the measures taken in planning based on the obtained results.
\end{abstract}

Keywords: Degree and Level of Development; Morris Model; Taxonomy Model; Coefficient of Variation; Regions in Isfahan

\section{Introduction}

The primary fundamental theory of economic development and underdevelopment developed during 1950s (DHV Engineering consultancy, 31, 1992). Discussions about (Development and Underdevelopment) and expansion of the scope of these discussions drew a large number of economists to the center of the debate. Economists who took part in the discussions about economic development can be divided into two groups. The first group is liberal economists such as Colin Clark, Benjamin Heginiz, Lord Robbins, Joan Robenson, John Kenneth Galbraith. The second group is socialists economists, and socialists raised and trained in the West such as Morris Edeb, Paul Baran, Harry Magraf, Gunnar Myrdal (Jirvand, 1996, 13).

Overall, since the issues of development and underdevelopment broke out, different schools and views about development and underdevelopment have been proposed including the evolutionary school of development of modernization theory, the Marxist view of development and dependency theory (Azkia, 2002, 35).

Studying each of these theories and views shows that the objective of each is to study and analyze the factors that help create and develop inequalities and imbalances in different countries and regions in spite of the important role that infrastructural services and facilities play in improving the development of rural areas (Izadi Farameh, 2001, 32). Providing and running all services and facilities in all settlements is neither necessary nor rational and logic (Rondinell,1998,115). Due to severe resource constraints and the need to determine investment priorities based on rational thinking and planning in these countries, it is attempted to invest and finance existing and available resources in the best location with the highest level of performance by adopt centralized policies such as creating and equipping such key or central settlements. The purpose of this policy which has been the focus of some development theories and came into force and was operated in the past decade especially since 1960 onwards in countries such as Brazil, Vietnam, Malaysia and Indonesia is to create a center or core which is prone to progressive growth and development and to prevent rural-urban immigrations by providing services (R. P. Mira, 1989, 46). However, there is a variety of quantitative methods and techniques for assessing and determining development which are used for organizing and assessing information depending on the degree of reliability and credibility of accessible information and the expertise and skills of 
local planners. Among these methods are Taxonomy analysis, factor analysis, cluster analysis, social network analysis, hierarchical analysis of Morris's model, and neural network model (Badri, 1990, 53). Meanwhile, with advances in geographical information system it has become possible to make spatial models and analyze information spatially (Faraji Sabolbar, 2005, 125). It is obvious that each of these methods is based on different theoretical approaches and grounds and thus provides different classifications. However, there is a common theme and subject in all of these classifications and that is the difference and contrast which is usually between elements that constitute a region (Copus Crabtree, 1999, 42).

\section{Theoretical Bases of the Research}

With a brief review of the theories of development and underdevelopment, two general frameworks are proposed: the basic fundamental framework and the modern framework of development. The evolutionary school of development, modernization theory, the Marxist view of development, and dependency theory are within the fundamental framework (Azkia, 2002, 35).

These schools whose intellectual roots largely refer to and are based on Keynesian economics believe in expanding the intervening role of government in development with the contribution of foreign aids (DHV Engineering consultancy, 1992, 31). In all these schools, the dominance of top-down approach and the ruling role of government in pursuing development planning (Sarrafi, 1998, 158) and the analytic and detailed component-oriented view in analyzing issues of using quantitative methods and mathematical models by planners are inevitable for the ease of understanding and recognizing the complexities of issues and problems in different areas (Afrakhte, 1998, 11). In this framework, the usual conventional measurements and actions for development are done by preparing technical design and its executor implementation which is known as (Azalydy approach) during which everything, including human beings, is seen as a variable. On this basis, analytical techniques are used that help planners with understanding the structure and function and as a result make predicting and modeling possible (Sarrafi, 1998, 13, 164). In contrast, modern frameworks of development emphasize on bottom-up approaches of development by accepting views such as of local communities, the role of non-governmental organizations (NGTO), gender issues of equality, democracy of citizenship participation and most importantly environment and sustainable development (Hodder, 2000, 10).

From the latter view and framework, man and human society are employed not as (objects for modifications and adjustments) but (factors in changes) and individuals are considered as "subjects of research" not "objects of research". Therefore, the requirement for true realization of development is the acceptance of (participatory and cooperative approach) with bottom-up bilateral or reciprocal movement. This framework pursues systematic set of relationships to address issues of public interest due to holistic view to issues and regarding understanding cause and effect relationships. It relies on qualitative methods as well as quantitative methods in order to offer understandable and clear results in decision-making by the public and it considers planning not a proving science and not severely normalizing which follows universal laws, but a science looking for rules which are specific to each case and are compatible with the culture of the region, as a result, depending on the nature, it mostly benefits from process techniques (Sarrafi, 1998, 164).

Anyway, the emergence of a new model based on the fundamental principles of social sciences which supports a variety of development experiences at different times and in different places with emphasis on the foundations of peoplecentered approach in the theory of sustainable development shifts and changes the role of government from the main constructive, providing and regulating role to the role of establishing legal powerful frameworks, delegating power, and encouraging synergies and cooperation (Shepherd,1999, 19). It looks for recognizing issues in a holistic framework and in this way it uses quantitative methods not as substitutes but as a means for facilitating the planning process and decision making.

\section{Research Method}

Regarding the aims of the research, descriptive applied and cross-sectional research method was used and the theoretical bases related to the subject were studied using attribute method. Then, in order to determine the levels of development in regions in Isfahan concerning the importance of indexes and access limitations to indexes, 30 variables were collected in the form of educational-cultural (the number of libraries, study halls, cultural centers), religious (the number of mosques), therapeutic (the number of health and therapeutic complexes), infrastructural (the number of beautification and ornamental elements, light stands, overpass bridges, underpass bridges, parking lots, in service parking lots), entertainment (the number of entertainment centers, bicycle stations, toys and amusement parks, safe playgrounds), green landscape (the number of city parks, local parks, green lands, neighborhood parks), sports (the 
number of indoors and outdoors sports centers), population (the number of male literates, female literates, total number of literates, urban density, number of households/families), and construction (the number of constructional mechanized building permits, issued building permits, business building permits, offices, etc) indexes. This data is obtained from the results of the 2011 Population Housing. To analyze the data and determine the level of development, Morris's and Taxonomy's models and to determine the distribution of facilities and services, the coefficient of variation CV were used.

\section{Recognizing the Study Area}

Isfahan province with an area of over 1107090 square kilometers (about 35.6 of the total area of the country) is located in the center of Iran plateau. The geographical location or situation of this province is between 31 degrees, 26 minutes to 34 and 30 minutes of north latitude and 49 degrees and 34 minutes to 55 degrees and 50 minutes of east longitude of the Greenwich meridian. According to the latest country divisions in 2006, Isfahan County has 21 provinces, 92 cities, 44 sections, 122 villages and over 1934 inhabited hamlets.

Isfahan city is over 276/2 square kilometers. Isfahan city with the 5 degrees and 39 minutes and 40 seconds of east longitude, and 32 degrees and 38 minutes and 30 seconds of north latitude is located in the center of Isfahan province on the path of one of the vital arteries of the country (Isfahan Governship, 2008, 45).

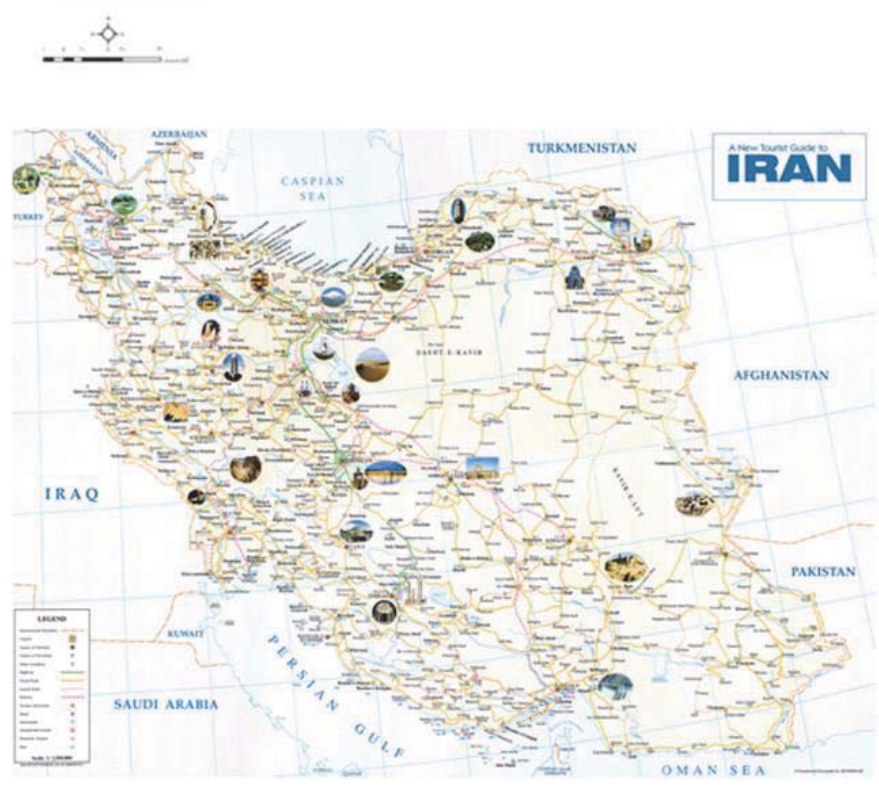

Map 1: Isfahan Province, Iran

Table 1: The data and the variables in determining the development level in Isfahan province

\begin{tabular}{|l|c|c|c|c|c|c|c|}
\hline Variable & \multicolumn{7}{|c|}{ Regions } \\
\hline & $\mathbf{1}$ & $\mathbf{2}$ & $\mathbf{3}$ & $\mathbf{4}$ & $\mathbf{5}$ & $\mathbf{6}$ & $\mathbf{7}$ \\
\hline 1. Number of libraries and study halls & 8 & 5 & 14 & 6 & 6 & 9 & 4 \\
\hline 2. Number of cultural centers & 10 & 2 & 10 & 5 & 3 & 7 & 5 \\
\hline 3.Number of indoors sports centers & 3 & 6 & 4 & 6 & 13 & 15 & 4 \\
\hline 4.Number of outdoors sports centers & 3 & 5 & 1 & 11 & 9 & 9 & 6 \\
\hline 5. Number of entertainment centers & 0 & 0 & 0 & 3 & 2 & 2 & 1 \\
\hline 6.Number of beautification and ornamental elements & 28 & 13 & 48 & 27 & 32 & 76 & 13 \\
\hline 7.Number of light stands & 38 & 0 & 26 & 0 & 46 & 35 & 37 \\
\hline 8-Number of bicycle station & 3 & 0 & 5 & 2 & 3 & 1 & 2 \\
\hline 9-Number of toys and amusement parks & 11 & 7 & 11 & 8 & 21 & 10 & 18 \\
\hline 10-Number of safe playgrounds & 10 & 5 & 10 & 6 & 19 & 8 & 16 \\
\hline 11.Number of health and therapeutic centers & 13 & 14 & 9 & 11 & 21 & 19 & 22 \\
\hline 12.Number of overpass bridges & 1 & 0 & 0 & 3 & 2 & 1 & 3 \\
\hline
\end{tabular}




\begin{tabular}{|l|c|c|c|c|c|c|c|}
\hline 13.Number of underpass bridges & 0 & 0 & 0 & 0 & 2 & 1 & 1 \\
\hline 14.Number of parking lots & 12 & 0 & 27 & 12 & 17 & 10 & 4 \\
\hline 15.Number of in service parking lots & 12 & 0 & 27 & 12 & 17 & 10 & 4 \\
\hline 16-Number of mosques & 76 & 54 & 210 & 51 & 38 & 88 & 88 \\
\hline 17-Number of city parks & 4 & 1 & 3 & 5 & 5 & 8 & 7 \\
\hline 18-Number of local parks & 0 & 4 & 7 & 11 & 2 & 12 & 9 \\
\hline 19-Number of green landscapes & 10 & 4 & 8 & 4 & 5 & 47 & 34 \\
\hline 20-Number of neighborhood parks & 0 & 4 & 7 & 11 & 2 & 12 & 9 \\
\hline 21-Number of male literates & 34068 & 27059 & 47860 & 55273 & 73169 & 49780 & 63865 \\
\hline 22-Number of female literates & 34406 & 24303 & 47067 & 53354 & 70009 & 48691 & 59948 \\
\hline 23-Number of total literates & 68474 & 51362 & 94927 & 108627 & 143178 & 98471 & 123813 \\
\hline 24-Urban density & 1105 & 493 & 1515 & 1868 & 1628 & 1192 & 1473 \\
\hline 25-Number of households/families & 25790 & 19787 & 26049 & 39868 & 48374 & 35803 & 35383 \\
\hline 26-Number of constructional mechanized building permits & 462 & 323 & 575 & 828 & 443 & 347 & 844 \\
\hline 27-Number of issued building permits & 1920 & 880 & 2033 & 3387 & 1898 & 0 & 2739 \\
\hline 28-Number of business building permits & 122 & 86 & 605 & 141 & 112 & 0 & 378 \\
\hline 29-Number of business office permits & 116 & 87 & 244 & 127 & 113 & 0 & 76 \\
\hline 30-Others & 276 & 942 & 2467 & 1684 & 465 & 0 & 1734 \\
\hline
\end{tabular}

Table 2: The data and the variables in determining the development level in Isfahan province

\begin{tabular}{|c|c|c|c|c|c|c|c|c|}
\hline Variable & & & & $\operatorname{Re}$ & jions & & & \\
\hline & 8 & 9 & 10 & 11 & 12 & 13 & 14 & 15 \\
\hline 1. Number of libraries and study halls & 5 & 7 & 10 & 6 & 5 & 6 & 4 & 8 \\
\hline 2. Number of cultural centers & 5 & 3 & 6 & 5 & 3 & 5 & 0 & 6 \\
\hline 3.Number of indoors sports centers & 5 & 6 & 10 & 3 & 3 & 5 & 4 & 7 \\
\hline 4.Number of outdoors sports centers & 5 & 6 & 7 & 4 & 11 & 10 & 6 & 1 \\
\hline 5. Number of entertainment centers & 1 & 0 & 1 & 0 & 1 & 1 & 0 & 1 \\
\hline 6.Number of beautification and ornamental elements & 11 & 12 & 20 & 19 & 20 & 15 & 8 & 15 \\
\hline 7.Number of light stands & 107 & 0 & 0 & 36 & 29 & 0 & 0 & 0 \\
\hline 8-Number of bicycle station & 3 & 1 & 1 & 0 & 1 & 2 & 1 & 0 \\
\hline 9-Number of toys and amusement parks & 23 & 10 & 21 & 9 & 20 & 12 & 12 & 31 \\
\hline 10-Number of safe playgrounds & 23 & 9 & 20 & 8 & 16 & 11 & 12 & 4 \\
\hline 11.Number of health and therapeutic centers & 18 & 9 & 22 & 16 & 29 & 21 & 13 & 31 \\
\hline 12.Number of overpass bridges & 0 & 0 & 2 & 0 & 1 & 0 & 0 & 0 \\
\hline 13.Number of underpass bridges & 0 & 0 & 0 & 0 & 0 & 2 & 1 & 3 \\
\hline 14.Number of parking lots & 3 & 3 & 4 & 1 & 0 & 2 & 3 & 1 \\
\hline 15.Number of in service parking lots & 3 & 3 & 4 & 1 & 0 & 2 & 3 & 1 \\
\hline 16-Number of mosques & 63 & 70 & 93 & 45 & 32 & 35 & 76 & 100 \\
\hline 17-Number of city parks & 11 & 7 & 13 & 3 & 7 & 9 & 3 & 7 \\
\hline 18-Number of local parks & 23 & 5 & 46 & 2 & 24 & 14 & 38 & 13 \\
\hline 19-Number of green landscapes & 53 & 2 & 47 & 13 & 20 & 31 & 7 & 13 \\
\hline 20-Number of neighborhood parks & 28 & 3 & 2 & 4 & 10 & 9 & 0 & 13 \\
\hline 21-Number of male literates & 102843 & 31345 & 91354 & 2418 & 53549 & 5226 & 67415 & 47163 \\
\hline 22-Number of female literates & 98243 & 28895 & 83468 & 21484 & 50676 & 49697 & 59727 & 42003 \\
\hline 23-Number of total literates & 201086 & 60240 & 174822 & 45602 & 104225 & 101958 & 127143 & 89166 \\
\hline 24-Urban density & 1201 & 686 & 2042 & 3052 & 2075 & 4026 & 6876 & 4382 \\
\hline 25-Number of households/families & 71060 & 22573 & 63910 & 17005 & 3739 & 35696 & 46772 & 33896 \\
\hline 26-Number of constructional mechanized building permits & 1088 & 456 & 773 & 198 & 760 & 428 & 680 & 8205 \\
\hline 27-Number of issued building permits & 3824 & 1369 & 2820 & 519 & 3108 & 959 & 2515 & 27971 \\
\hline 28-Number of business building permits & 328 & 64 & 165 & 76 & 319 & 30 & 201 & 2627 \\
\hline 29-Number of business office permits & 260 & 40 & 91 & 8 & 81 & 9 & 106 & 1358 \\
\hline 30-Others & 119 & 699 & 2823 & 449 & 2951 & 209 & 1242 & 26060 \\
\hline
\end{tabular}

\section{The Structure of Methods for Measuring the Degree of Development}

As mentioned in the theoretical foundations, programming techniques can be classified into two groups: analysis techniques and process techniques. In the present article, the method known as "a set of indexes' analysis" is used among different methods of analytical techniques which are mainly rooted in other sciences, especially natural sciences and physics. These kinds of methods are very common for measuring regional differences. However, special attention must be paid to standardization, and comparability of indexes, and non-repeating indexes. (Sarrafi, 1998, 167). 


\section{Morris's Method}

Morris's method specifies the level of development by using descriptive data for each settlement unit compared to other units and the utilizing the following two parameters:

1 -

$Y i j=\frac{x i j-x i j \min }{x i y \max -x i j \min }$

In this formula

$Y i j=$ uneven or imbalanced index for $i^{\text {th }}$ variable in $j^{\text {th }}$ unit

$x i j=j^{\text {th }}$ variable in the $j^{\text {th }}$ unit

$x i j$ min $=$ the minimum value of $\mathrm{i}^{\text {th }}$ variable

$x i j \max =$ the maximum value of the $i^{\text {th }}$ variable (Rezvani, 2004, 153).

The important point is that in this approach the used indexes must be aligned or in the same direction. To investigate the issue, all the considered indexes or parameters are used in the above formula (Ghadiri, 1998, 269).

2-The main index of development is calculated by the formula: ${ }^{D I=\sum_{n=1}^{n} \frac{y i j}{n}}$

Where $\mathrm{n}$ is the number of studied indexes and DI is the main or key index of development. Morris's development index coefficient varies from zero to 100 , the closer it is to 100, the higher the level of development (Rezvani, 2004, 154).

\section{Taxonomy's Model}

Taxonomy's model is another method for assessing or measuring the degree of development in regions. It was first proposed by Anderson in 1763 and was introduced by Professor Heloving from the Higher School of Economics in UNESCO In 1968 as a means for classification of the degree of development among nations (Ziari, 2001, 137). This method is able to divide a set into a more or less homogenous subset to determine units or kinds of homogenous subjects in a three-dimensional vector space or environment without using variance regression and correlation analysis. Therefore, this method can be used as an appropriate framework or criterion for understanding the aspects and dimensions of social and economic growth and development in the region (Badri, 1990, 89).

\section{Coefficient of Variation Method}

In order to assess and measure how much or to what extent the value of an index is distributed in an unbalanced way among different regions, coefficient of variation method C.V is used. The coefficient of variation is calculated using the following formula: (Kalantari, 2001, 12).

$C . V=\frac{\sqrt{\sum_{i=1}^{n} \frac{\left(x_{1}-\bar{x}\right)}{N}}}{\sum_{i=1}^{n} \frac{x_{1}}{N}}$

$C . V$ =the value of the coefficient of the variations of an index

$x_{1}=$ the value of an index in a region

$\bar{x}=$ the means of an index

$\mathrm{N}=$ number of regions

In this method, a high CV value indicates greater inequality in the distribution of the considered index.

\section{Research Results}

Using the collected data in the form of 9 development indexes (30 variables) and according to Morris's and Taxonomy's model, the development coefficient is calculated for each region of the province. The results of the investigation show that the development coefficient varies from a minimum of 2.10 to a maximum of 10.08 so that Region 4 with the coefficient of 10.08 in Morris's model and 0.62 in Taxonomy's model has the highest development coefficient and Region 13 with the coefficient of 2.10 in the Morris's model and 0.977 in Taxonomy's model has the lowest development coefficient among the regions of the province. 
Table 3: Development coefficient and the ranking of Isfahan regions

\begin{tabular}{|c|c|c|c|c|}
\hline & \multicolumn{2}{|c|}{ Morris Model } & \multicolumn{2}{c|}{ Taxonomy Model } \\
\hline Region & Coefficient & Ranking & Coefficient & Ranking \\
\hline 1 & 2.57 & 10 & 0.789 & 10 \\
\hline 2 & 2.62 & 8 & 0.75 & 8 \\
\hline 3 & 2.49 & 13 & 0.865 & 13 \\
\hline 4 & 10.08 & 1 & 0.62 & 1 \\
\hline 5 & 5.42 & 3 & 0.662 & 3 \\
\hline 6 & 2.43 & 14 & 0.869 & 14 \\
\hline 7 & 2.83 & 6 & 0.72 & 6 \\
\hline 8 & 3.13 & 5 & 0.718 & 5 \\
\hline 9 & 2.52 & 12 & 0.847 & 12 \\
\hline 10 & 7.66 & 2 & 0.638 & 2 \\
\hline 11 & 2.63 & 7 & 0.73 & 7 \\
\hline 12 & 2.54 & 11 & 0.818 & 11 \\
\hline 13 & 2.10 & 15 & 0.977 & 15 \\
\hline 14 & 2.60 & 9 & 0.76 & 9 \\
\hline 15 & 3.17 & 4 & 0.68 & 4 \\
\hline
\end{tabular}

\section{The Level of Development of Regions in Isfahan}

Given the development coefficient, the regions were classified into four levels of developed (privileged), developing (semi-privileged), relatively developed and less developed (underprivileged or deprived) regions.

According to this classification, the development coefficient of building or construction indexes has the highest and the development coefficient of health and therapeutic indexes has the lowest rate of variation. By studying the coefficient of variation $\mathrm{CV}$ of the studied indexes, it is understood that health indexes and educational, cultural, and religious indexes have the lowest rate of imbalance in the distribution of facilities and services and infrastructural, entertainment, green landscapes, population, and sports indexes are in the next rankings.

Table 4: Development of Isfahan regions based on the applied methods

\begin{tabular}{|c|l|l|}
\hline Region & Morris & Taxonomy \\
\hline 1 & Less developed & Relatively developed \\
\hline 2 & Less developed & Developed \\
\hline 3 & Less developed & Developed \\
\hline 4 & Developed & Developed \\
\hline 5 & Developed & Relatively developed \\
\hline 6 & Less developed & Relatively developed \\
\hline 7 & Developing & Relatively developed \\
\hline 8 & Developing & Relatively developed \\
\hline 9 & Less developed & Relatively developed \\
\hline 10 & Developed & Relatively developed \\
\hline 11 & Developing & Less developed \\
\hline 12 & Less developed & Less developed \\
\hline 13 & Less developed & Less developed \\
\hline 14 & Less developed & Relatively developed \\
\hline 15 & Developed & Developed \\
\hline
\end{tabular}

Table 5: Development coefficient and ranking of Isfahan regions regarding the studied indexes

\begin{tabular}{|l|c|c|c|c|c|c|c|c|c|}
\hline Rank Indexes & $\begin{array}{c}\text { Educational- } \\
\text { cultural }\end{array}$ & Religious & $\begin{array}{c}\text { Health and } \\
\text { Therapeutic }\end{array}$ & Sports & $\begin{array}{c}\text { Green } \\
\text { Landscape }\end{array}$ & Entertainment & Infrastructural & Population & $\begin{array}{c}\text { Building } \\
\text { or } \\
\text { Structural }\end{array}$ \\
\hline Coefficient of Variation & 0.7 & 0.56 & 0.36 & 1.06 & 3.09 & 2.52 & 5.21 & 1.47 & 7.03 \\
\hline
\end{tabular}




\section{Conclusion}

In the process of urban development planning, understanding and recognizing facilities' analysis and obstructs and blockages in urban areas, and grading these areas regarding the rate of privilege and deprivation are of great importance which must always be considered. Therefore, in the present article the development coefficient of urban regions and areas in Isfahan province is studied and determined using 30 variables of development indexes in Morris's and Taxonomy's models. Eventually, the regions of the province were classified into 4 levels of developed, developing, relatively developed, and less developed or underdeveloped regions. The results of study show that development coefficient in regions is different and unequal and some regions lack privileges regarding facilities and services. In addition, based on the calculation of coefficient of variation among the studied indexes, the health and therapeutic index suffers more imbalance and inequality in comparison to other indexes. The correlation coefficient and significance level of the studied factors show that the decrease in the distance from the city center has an effective role in the increase in development coefficient. According to the results, in order to achieve sustainable development, it is necessary to recognize potentials, capabilities and competences of the regions for fundamental purposeful planning and to design a hierarchical service system by organizing rural areas to minimize inequalities and restrictions on the way of urban sustainable development as far as possible.

\section{References}

Afrakhte, Hassan. 1995. Model in Geography. First edition. Jahad Daneshgahi Publications. ZahedanAsayesh, Hossein and Alireza Estelaji. 2004. Principles and methods of regional planning (models, methods, and techniques). First edition. Shahre Rey Azad University Publications.

Ashtari, Hamid. 1994. Determining the degree of development of regions in Azarbayjan Gharbi province (Province, Urban, and Rural). Thesis dissertation. Supervisor: Mohammad Hossein.

Azkia, Mostafa. 2002. Development sociology and rural underdevelopment in Iran. Sixth edition. Etelaat Publications, Tehran.

Borzooyan, Samad. 1995. Determining the degree of development in cities in Mazandaran province. Master thesis dissertation. Supervisor: Morteza Gharah Baghian. Tarbiat Modares University. Tehran.

Copus,Aa.k. \& G.R. Crabtree. (1996). Indicators of socio-economic sustainability: an application to remote rural Scotland, Journal of Rural Studies,vol.12,no.1,pp-41-54.

Eslami, Seifollah. 1993. Determining the degree of development in Iran's rural areas. Master thesis dissertation. Supervisor: Abbas Mazar. Shahid Beheshti University.

Faraji Sabokbar, Hassanali. 2005. Location finding of business service units using analytical hierarchical process (AHP) method, a case study in Torghabe region in Mashhad city. Geographical Research Journal (Tehran University), No. 51, Spring 2005, pp.125-138.

Ghadiri Maasoom, Mojtaba. 1998. Finding geographical potentials in Iran, economic development planning in Dashte Moghan. PH.D. dissertation. Human geography department, geography and rural planning field. Supervisor: Professor Rahmatollah Farhoodi. Tehran Unicersity.

Hosseinzadeh, Dalir Karim. 1996. Regional planning. First edition. Samt Publications. Tehran.

Iran's statistics center. 2011. The results of General Census of Population and Housing In Isfahan.

Jirvand, Abdollah. 1996. Economic development (Believes collection). Sixth edition. Molavi Publications. Tehran.

Kalantari, Khalil. 2001. Planning and regional development (theory and techniques). First edition. Khoshbin Publications. Tehran.

Kalantari, Khalil. 2001. A criticism on the methodology of assessing human resources UNDP. Geography research Quaeterly, 16th year, No.1, Summer 2001, pp.153-166.

Mansoor Sales, Mohammad. 1996. Measuring the degree of development in cities in Tehran province. Master thesis dissertation. Supervisor: Hossein Poorkazemi. Shahid Beheshti University.

Mazrooi, Rajabali. 1994. Determining the degree of development in cities in Isfahan province. Master thesis dissertation. Supervisor: Abbas Mazar. Shahid Beheshti University.

Misra, R. P. 1994. Discussions on rural development. Jahad Journal. No. 115.

Rezvani, Mohammad Reza. 2004. Assessing and analyzing development in rural areas in Sanandaj city. Geography region and regional development, No. 3. Mashhad University.

Roknodin Efrekhari, Abdolreza, and Hassan Izadi Kharameh. 2001. An analysis on location finding approach and distribution of services in rural areas, studying urban functions approach in rural development and spatial allocation model. Geographical Research Journal, $16^{\text {th }}$ series, Autumn 2001, No. 3., pp. 30-66.

Rondinelli, Dennis A.(1998). Equity, Growth and Development Regional Analysis in Developing countries.

Saaraki, Naser. 1995. Determining the degree of development in cities in Kermanshah province. Master thesis dissertation. Supervisor: Morteza Gharah Baghian. Tarbiat Modares University. Tehran.

Saeedi, Abbas. 1997. The necessity of locational-spatial arrangement in rural settlements in line with organizing dispersed villages. The articles collection of organizing dispersed villages conference. November 1996. Islamic revolution housing/settlement assembly. pp. 415-460. 
Sarrafi, Mozafar. 1998. The principles of regional development planning. 16th serie of budget and planning collection. Economic and social documents center of budget and planning organization.

Shokooee, Hossein. 1996. New insights in geography philosophy. Vol. 1. First edition. Gitashenasi Publicaitons. Tehran.

Ziadi, Keramatollah. 1999. Principles and methods of regional planning. First edition. Yazd University Publications. 